\title{
17q21 variants modify the association between early respiratory infections and
} \section{asthma}

\author{
L.A.M. Smit*,\#,ף, E. Bouzigon ${ }^{+, \S, f}$, I. Pin**,\#\#,ףฯ, V. Siroux**,\#\#, F. Monier*,\#, \\ H. Aschard ${ }^{+, \S, f}$, J. Bousquet*, ${ }^{*,++}$, F. Gormand ${ }^{\S \S}$, J. Just ${ }^{f f}$, N. Le Moual*,\#, R. Nadif*,\#, \\ P. Scheinmann***, D. Vervloet ${ }^{\# \# \#}$, M. Lathrop ${ }^{f, \uparrow}$, F. Demenais ${ }^{+, \S, f}$, F. Kauffmann*,\# \\ and the EGEA Cooperative Group ${ }^{+++}$
}

ABSTRACT: Single nucleotide polymorphisms (SNPs) at chromosome 17q21 confer an increased risk of early-onset asthma. The objective was to study whether 17q21 SNPs modify associations between early respiratory infections and asthma.

Association analysis was conducted in 499 children (268 with asthma, median age 11 yrs) from the Epidemiological Study on the Genetics and Environment of Asthma (EGEA). The 12-yr followup data were used to assess persistent or remittent asthma in young adulthood. Respiratory infection before 2 yrs of age was assessed retrospectively.

For the 12 17q21 SNPs studied, the odds ratios (OR) for association between infection and early-onset asthma (age at onset $\leqslant 4$ yrs) were higher in carriers of risk genotypes (OR 3.42-6.36) than in noncarriers (OR 1.84-2.44; p-value for interaction 0.02-0.04 for five SNPs). Risk genotypes also increased the association between infection and childhood asthma that remits in adulthood (OR 4.84-7.16 in carriers and 1.74-2.25 in noncarriers; p-value for interaction 0.008-0.05 for 10 SNPs). In children with 17q21 risk genotypes and early-life environmental tobacco smoke (ETS) exposure, associations between infection and asthma were further enhanced.

17q21 genetic variants and early ETS exposure enhance the association between early respiratory infections and early-onset asthma and childhood asthma that remits in adulthood.

KEYWORDS: Environmental tobacco smoke exposure, epidemiology, gene-environment interaction, GSDML, ORMDL3, respiratory infection

nfants with early lower respiratory tract infections, which are mainly caused by viruses, such as respiratory syncytial virus (RSV) or rhinovirus, are at increased risk of recurrent wheezing and childhood asthma [1-4]. It is not clear whether respiratory infection is a marker identifying infants with a predisposition to develop asthma, or whether infection is causally related to the inception of asthma $[5,6]$. Early life is a crucial period for lung development, and it has been argued that viral infection itself may actually increase the risk of asthma by influencing the development of immune response or by altering lung function $[4,7,8]$. However, a recent Danish twin pair study found no evidence to support a causal role of infection [6].

Only a minority of infants with respiratory viral infections such as bronchiolitis develop recurrent wheezing and asthma, suggesting that genetic and environmental factors may influence the association between asthma and infection [9]. For instance, exposure to environmental tobacco smoke (ETS) may play such a role [10]. Single nucleotide polymorphisms (SNPs) in innate immunity and other immune response genes, have been shown to be associated with severity of RSV bronchiolitis [11, 12], however there is a lack of studies investigating genetic factors that influence the association between bronchiolitis and asthma [9].

A genome-wide association study (GWAS) has shown associations between SNPs on chromosome 17q21 and childhood asthma [13], which has been replicated by several studies [14-17]. In the Epidemiological Study on the Genetics and Environment of Asthma (EGEA) it has been
AFFILIATIONS

*INSERM Unité 780

\#Université Paris-Sud, IFR69, Villejuif, +INSERM Unité 946,

ङUniversité Paris Diderot, Paris 7 Institut Universitaire d'Hématologie, ${ }^{f}$ Fondation Jean Dausset-CEPH,

${ }^{f}$ Hôpital Trousseau, APHP, Université Paris 6 ,

***Hôpital Necker, Faculté de Médecine Paris Descartes, Paris, **INSERM Unité 823

\#\# Université Joseph Fourier,

"Centre Hospitalier Universitaire de Grenoble, Grenoble,

${ }^{++}$Hôpital Arnaud de Villeneuve, Montpellier,

${ }^{\S \S}$ Centre Hospitalier Lyon-Sud, Pierre Bénite,

\#\#\#Hôpital Ste Marguerite, Marseille,

"Commissariat à I'Energie Atomique Institut de Génomique, Centre National de Génotypage, Evry, France. "IRAS, Utrecht University, The Netherlands.

${ }^{++}$For a list of the EGEA Cooperative Group members see the

Acknowledgements.

\section{CORRESPONDENCE}

L.A.M. Smit, Institute for Risk Assessment Sciences, Division of Environmental Epidemiology, Utrecht Univeristy, P.0. Box 80178, Utrecht, The Netherlands

E-mail: L.A.Smit@uu.nl

Received:

Sept 302009

Accepted after revision: Dec 082009

First published online: Dec 232009 
shown that the increased risk conferred by $17 q 21$ variants was restricted to early-onset asthma, and was further enhanced by early life ETS exposure [16]. The latter finding was recently replicated in white subjects [18]. It is still unclear how these genetic variants influence the risk of asthma. Interestingly, the expression of one of the 17q21 genes, ORMDL3, was found to be strongly induced by stimulation with polyinosinepolycytidylic acid in lung fibroblasts, suggesting that ORMDL3 might play a role in viral respiratory infections [14]. Thus, interactions between 17q21 variants and early life events appear to play an important role in the development of earlyonset asthma. It is, however, not known whether these effects persist after childhood.

The objective of the present study was to test the following two hypotheses: 1) the association between early respiratory infections and asthma, particularly early-onset asthma, is influenced by genetic variants in the 17q21 region; and 2) the modifying effect of 17q21 variants on the association between infections and early-onset asthma is further increased by ETS exposure in early life. Furthermore, we tested the same hypotheses for two additional asthma phenotypes: childhood asthma that was either persistent or remittent in young adulthood.

\section{METHODS}

\section{Study population and design}

EGEA combines a case-control study and a family study. The design and protocol have been reported in detail elsewhere [19]. Probands (asthmatic patients aged 7-70 yrs) were recruited from six chest clinics in five French cities between 1991 and 1995 (EGEA1). Family members of asthmatic probands were included, either by including the proband's parents and siblings or by including the proband's spouse and children. In addition, population-based controls were recruited.

In the present study, association analyses were conducted in children (age $\leqslant 16$ yrs) from the EGEA families and control sample. Of the 604 children enrolled at EGEA1, we used data from 499 children (268 with asthma, 231 without asthma) who had complete information on 17q21 genotypes, age at onset of asthma and respiratory infections (fig. E1 in the supplementary material). A 12-yr follow-up of EGEA1 has been conducted recently (EGEA2; 2003-2007) [20]. Activity of asthma at EGEA2 was obtained in 236 (88\%) out of 268 children with asthma at EGEA1.

All participants or their parents gave written informed consent.

\section{Genotyping}

Genotyping has been described previously [16]. In the present study, we examined the 11 SNPs located between 35.23 and $35.34 \mathrm{Mb}$ on chromosome 17q21 that were significantly associated with asthma $(\mathrm{p}<0.01)$ in EGEA families [16]. We also included an additional SNP, rs7216389, since it was the most studied $17 \mathrm{q} 21$ variant in replication studies subsequent to the initial GWAS [13]. The 12 SNPs were in strong linkage disequilibrium (LD) with one another, with pairwise LD coefficient $\mathrm{D}^{\prime}$ between 0.87 and 1.0 [16].

\section{Health outcomes and exposure variables}

Inclusion criteria used at EGEA1 to define asthma in probands, and the definition of asthma in relatives or population-based controls have been described before [19, 21]. Early-onset asthma was defined as being $\leqslant 4$ yrs old at the onset of asthma [16]. A self-completed questionnaire was used to assess whether children with asthma at the first survey still had active asthma at EGEA2, which was defined as having had an asthma attack or used asthma medication during the last 12 months. In subjects with asthma at EGEA1, persistent and remittent asthma in young adulthood were defined according to activity of asthma (yes/no) at EGEA2. Subjects without asthma at EGEA1 were the reference group in all analyses.

Respiratory infection in early life was based on parental report at EGEA1, and defined as a positive answer to the question "Did your child have bronchitis or bronchiolitis before the age of 2?". ETS exposure in early life ( $\leqslant 2$ yrs of age) was defined as described previously [16].

\section{Statistical analysis}

Odds ratios (OR) and 95\% CI for association between infection and asthma were estimated by using generalised estimating equations approach with the logit link function to take into account family dependence among siblings. The sibship was defined as the cluster unit. OR were adjusted for age and sex. To test whether the association of infection with asthma was influenced by 17q21 genetic variants, we introduced the infection effect, the SNP effect, and an SNP $x$ infection term in the model while adjusting for age and sex. For 17q21 SNPs, we assumed a recessive genetic model (homozygous risk allele genotype versus other genotypes) which provided the best fit for association between the 17q21 locus and early-onset asthma as found previously [16]. The SNP $\mathrm{x}$ infection interaction was tested by using the generalised score test which follows a Chisquared distribution with one degree of freedom. We used the delta beta statistic to identify influential observations and we assessed the effect of excluding these observations on the results. Empirical p-values for tests of interaction between SNP and infection were also computed by simulations (i.e. marker genotypes were simulated under the null hypothesis of no SNP $x$ infection interaction by using the observed marker allele frequencies and LD pattern among SNPs and keeping the observed phenotypic data in the EGEA children). For each $\mathrm{SNP}$, the p-value was estimated by the proportion of 1,000 simulations leading to a test statistic for interaction as large as or larger than the one observed. Finally, we also tested whether the relationship between infection and asthma was modified by both 17q21 variants and exposure to ETS in early life, using a similar strategy.

\section{RESULTS}

\section{Descriptive characteristics}

Characteristics of study subjects with and without asthma at recruitment (EGEA1) are presented in table 1. As expected, objectively measured markers of asthma, such as atopy, total immunoglobulin (Ig)E, peripheral blood eosinophils, forced expiratory volume in $1 \mathrm{~s}$ (FEV1) and bronchial hyperresponsiveness were significantly associated with diagnosed asthma $(p<0.05)$. The median age of the study subjects at the second survey (EGEA2) was 22.4 yrs (interquartile range 20.0-24.2 yrs). 
Of 167 children with early-onset asthma, 84 had persisting asthma, 62 had remittent asthma and 21 had missing data at the second survey. Of 101 children with late-onset asthma, 44 had persistent asthma, 46 had remittent asthma and 11 had missing data at the second survey.

\section{Early infections}

Early respiratory infection was significantly associated with all asthma phenotypes, but most strongly with early-onset asthma and asthma remittent in young adulthood (table 2). OR changed only marginally after adjusting for age and sex. Further adjustment for ETS or atopy did not change the associations. Associations between respiratory infection and asthma appeared stronger in boys than in girls: the OR for the association between infection and early-onset asthma was 3.70 (2.17-6.32) in boys and 2.29 (1.14-4.59) in girls, but were not significantly different $(p=0.43)$. There was no association between the 17q21 SNPs and early respiratory infection ( $p>0.1$, data not shown). There were also no associations between 17q21 SNPs and infection when stratified analyses were performed in children with asthma (OR between 0.85 and
$1.57 ; \mathrm{p}>0.1$ ) or without asthma (OR between 0.59 and 0.84 ; $\mathrm{p}>0.1)$.

\section{Influence of 17q21 genotype on the association of infection with asthma}

The association between respiratory infection and early-onset asthma was stronger in carriers of risk genotypes for each of the 12 17q21 genetic variants (OR ranged between 3.42 and 6.36, according to the genetic variant) than in noncarriers (OR between 1.84 and 2.44) (table 3). Statistically significant interaction between infection and 17q21 genotype was observed for five SNPs $(p=0.02-0.04$; table 3$)$. In contrast, associations between infection and asthma with onset at age $\geqslant 5$ yrs did not differ significantly according to genotype; OR observed in carriers of risk genotypes were 0.7 -fold to 1.7 -fold OR observed in noncarriers ( $\mathrm{p}$-values for interaction ranging between 0.29 and 0.93 ; data not shown).

We then examined children with asthma in childhood with active or nonactive asthma in young adulthood (persistent or remittent asthma versus no asthma in childhood). OR for the association between infection and childhood asthma that remits in adulthood were 2.1-3.7-times higher in children with

\section{TABLE 1 Characteristics of the study population}

\begin{tabular}{|c|c|c|c|}
\hline Variable & $\begin{array}{l}\text { Data available for } \\
\text { all children }\end{array}$ & $\begin{array}{l}\text { Children with } \\
\text { asthma }\end{array}$ & $\begin{array}{c}\text { Children withou } \\
\text { asthma }\end{array}$ \\
\hline \multicolumn{4}{|l|}{ Recruitment category } \\
\hline Probands & & $164(61.2)$ & $0(0)$ \\
\hline Relatives & & $96(35.8)$ & $173(74.9)$ \\
\hline Age at recruitment yrs & 499 & $10.8(9.0-12.9)$ & $11.4(8.7-13.5)$ \\
\hline Respiratory infection in early life & 499 & $138(51.5)$ & $66(28.6)$ \\
\hline Exposure to ETS in early life & 489 & $122(46.6)$ & $114(50.2)$ \\
\hline Atopy $^{\#}$ & 486 & $226(86.6)$ & $91(40.4)$ \\
\hline In sensitised children, $\geqslant 2$ positive SPT & & 166 (73.5) & $47(51.6)$ \\
\hline $\operatorname{IgE}^{*} \mathrm{IU} \cdot \mathrm{mL}^{-1}$ & 489 & $383(151-815)$ & $58(21-177)$ \\
\hline Bronchial hyperresponsiveness $^{+}$ & 310 & $127(92.0)$ & $75(43.6)$ \\
\hline Used inhaled corticosteroids in the last 12 months & 494 & $102(38.5)$ & $2(0.9)$ \\
\hline Ever hospitalised for asthma & 267 & $72(27.0)$ & \\
\hline Age at onset of asthma yr & 268 & $4(2-6)$ & \\
\hline Early-onset asthma ( $\leqslant 4$ yrs old) & & $167(62.3)$ & \\
\hline Late-onset asthma ( $>4$ yrs old) & & $101(37.8)$ & \\
\hline Asthma persisting in young adulthood (persistent asthma) & 236 & $128(54.2)$ & \\
\hline Early onset in subjects with persistent asthma & & $84(65.6)$ & \\
\hline Late onset in subjects with persistent asthma & & $44(34.4)$ & \\
\hline Asthma inactive in young adulthood (remittent asthma) & 236 & $108(45.8)$ & \\
\hline Early onset in subjects with remittent asthma & & $62(57.4)$ & \\
\hline Late onset in subjects with remittent asthma & & $46(42.6)$ & \\
\hline
\end{tabular}

Data are presented as $\mathrm{n}, \mathrm{n}(\%)$ or median (interquartile range). ETS: environmental tobacco smoke; SPT: skin prick test; Ig: immunoglobulin; FEV1: forced expiratory volume in $1 \mathrm{~s}$; \% pred: \% predicted. ${ }^{*}$ : atopy was defined as a positive SPT to at least one of 11 common allergens; " : total serum IgE was measured by immunoassay: + : bronchial hyperresponsiveness was defined as $\geqslant 20 \%$ decline of FEV 1 for a methacholine cumulative dose $\leqslant 4 \mathrm{mg}$. 


\begin{tabular}{|c|c|c|c|c|}
\hline \multirow{2}{*}{$\begin{array}{l}\text { TABLE } 2 \\
\text { Phenotype }\end{array}$} & \multicolumn{4}{|c|}{$\begin{array}{l}\text { Association of asthma phenotypes and early } \\
\text { respiratory infection }\end{array}$} \\
\hline & & $\begin{array}{l}\text { Subjects } \\
n\end{array}$ & $\begin{array}{l}\text { Infection } \\
\text { prevalence }\end{array}$ & OR $(95 \% \mathrm{Cl})^{\#}$ \\
\hline \multicolumn{2}{|l|}{ No asthma } & 231 & $66(28.6)$ & 1.0 (reference) \\
\hline \multicolumn{2}{|l|}{ Asthma } & 268 & $138(51.1)$ & $2.49(1.73-3.58)$ \\
\hline \multicolumn{2}{|c|}{ Early-onset asthma } & 167 & $93(55.7)$ & $2.86(1.88-4.35)$ \\
\hline \multicolumn{2}{|c|}{ Late-onset asthma } & 101 & $45(44.6)$ & $2.09(1.29-3.39)$ \\
\hline \multicolumn{2}{|c|}{$\begin{array}{l}\text { Asthma persistent in } \\
\text { adulthood }\end{array}$} & 128 & $61(47.7)$ & $2.14(1.38-3.32)$ \\
\hline \multicolumn{2}{|c|}{$\begin{array}{l}\text { Asthma remittent in } \\
\text { adulthood }\end{array}$} & 108 & $59(54.6)$ & $2.93(1.87-4.59)$ \\
\hline
\end{tabular}

Data are presented as $n(\%)$, unless otherwise stated. ${ }^{*}$ : adjusted for age and sex; ${ }^{`}$ : subjects without asthma at EGEA1 were the reference group in all analyses.

risk genotypes than in children with nonrisk genotypes (OR ranged between 4.84 and 7.16 in carriers and between 1.74 and 2.25 in noncarriers; p-value for interaction $0.008-0.05$ for 10 SNPs) (table 4). The association between infection and childhood asthma persisting into young adulthood was not significantly modified by 17q21 SNPs (OR differed by a factor of $0.9-1.9$, p-value for interaction ranging from $0.18-0.91$; data not shown).

The delta beta statistic did not identify individuals who had a strong influence on the effect estimates shown in tables 3 and 4. We estimated the parameters of the model again without the 10 most influential observations. The p-values for interaction that were $<0.05$ in table 3 still reached that significance level, except for rs8076131 ( $p=0.07)$; and the $p$-values for interaction that were $<0.05$ in table 4 still reached that significance level, except for rs903281 ( $\mathrm{p}=0.08)$, rs4795405 $(\mathrm{p}=0.07)$ and $\mathrm{rs} 4794820$ $(\mathrm{p}=0.11)$.

\section{ETS exposure}

We further studied the influence of both 17q21 genotypes and ETS exposure in early life on the associations between respiratory infection and asthma. Figure 1 shows association between infection and either early-onset asthma or remittent asthma according to ETS exposure and risk genotype at rs8069176; the SNP showing the most significant geneenvironment interactions. The association between infection and early-onset asthma and remittent asthma was very strong among ETS exposed subjects with the rs8069176 GG genotype (early-onset asthma OR 9.98 (3.56-27.97), asthma remittent in adulthood OR 10.68 (3.58-31.82)). OR for the association between infection and early-onset asthma were significantly different between children exposed to ETS and children not exposed to ETS, but only in carriers of the risk genotype (interaction infection $\mathrm{x}$ ETS; $\mathrm{p}=0.03$ in children carrying rs8069176 GG). The other 11 SNPs showed similar patterns, with a very strong association between infection and earlyonset asthma among children exposed to ETS and carrying the risk genotype (ORs ranged between 4.65 (1.62-13.34) for rs9303277 CC and 10.04 (3.63-27.69) for rs2305480 GG), and weaker associations in the other children (data not shown).

Estimation of the parameters of the model without the 10 most influential observations led to a slight decrease in evidence for associations between infection and early-onset asthma: among ETS-exposed subjects with the rs8069176 GG genotype, the OR was 9.18 (3.06-27.6).

\section{DISCUSSION}

This study shows that $17 \mathrm{q} 21$ risk genotypes increased the positive association between early respiratory infection and asthma, and this was restricted to early-onset asthma and asthma that remits in young adulthood. The association

TABLE 3 Association of early-onset asthma and early respiratory infection in children, according to 17q21 SNPS

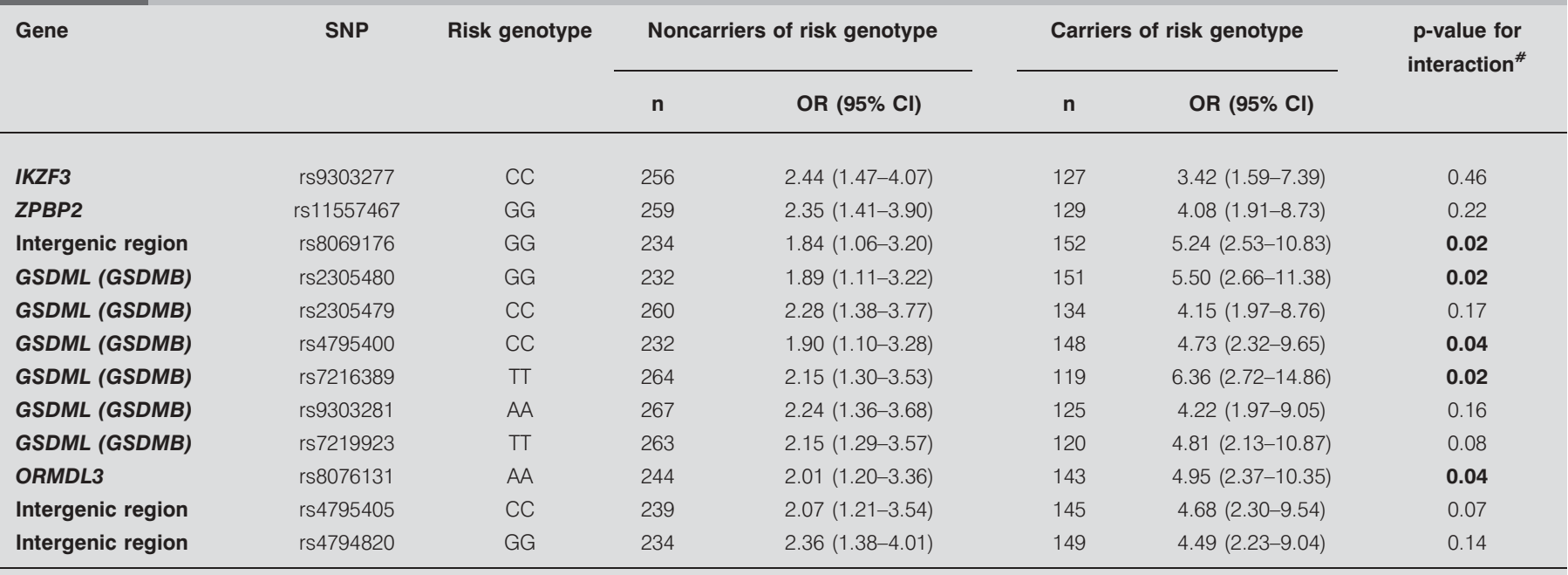

SNP: single nucleotide polymorphisms. ${ }^{*}$ : p-values for association of early-onset asthma and infection ranged between $0.03 \times 10^{-4}$ and $7.5 \times 10^{-4}$ in subjects with the nonrisk genotype and between $1.4 \times 10^{-3}$ and $4.6 \times 10^{-6}$ in subjects with the risk genotype. The p-values for interaction that were $<0.05$ in this table still reached that significance level when they were obtained by simulations, except for rs8076131 $(p=0.06)$. Bold values indicate significance. 
TABLE 4 Association of asthma remittent in adulthood and early respiratory infection in children, according to 17q21 SNPS

\begin{tabular}{|c|c|c|c|c|c|c|c|}
\hline Gene & SNP & Risk genotype & \multicolumn{2}{|c|}{ Noncarriers of risk genotype } & \multicolumn{2}{|c|}{ Carriers of risk genotype } & p-value for interaction ${ }^{\#}$ \\
\hline IKZF3 & rs9303277 & $\mathrm{CC}$ & 234 & $2.25(1.35-3.77)$ & 93 & $4.84(1.94-12.03)$ & 0.14 \\
\hline ZPBP2 & rs11557467 & GG & 235 & $2.02(1.20-3.38)$ & 99 & $5.66(2.33-13.76)$ & 0.04 \\
\hline Intergenic region & rs8069176 & GG & 214 & $1.74(1.00-3.01)$ & 117 & $6.37(2.78-14.58)$ & 0.008 \\
\hline GSDML (GSDMB) & rs2305480 & GG & 209 & $1.90(1.11-3.24)$ & 115 & $6.86(2.96-15.90)$ & 0.008 \\
\hline GSDML (GSDMB) & rs7216389 & $\pi T$ & 238 & $2.06(1.25-3.41)$ & 97 & $7.16(2.78-18.44)$ & 0.02 \\
\hline GSDML (GSDMB) & rs9303281 & AA & 236 & $2.17(1.31-3.62)$ & 94 & $6.03(2.39-15.21)$ & 0.05 \\
\hline GSDML (GSDMB) & rs7219923 & $\pi$ & 219 & $2.09(1.25-3.51)$ & 110 & $6.65(2.52-17.51)$ & 0.03 \\
\hline ORMDL3 & rs8076131 & AA & 218 & $2.01(1.19-3.38)$ & 111 & $6.12(2.58-14.50)$ & 0.02 \\
\hline Intergenic region & rs4795405 & $\mathrm{CC}$ & 214 & $1.99(1.18-3.38)$ & 118 & $5.63(2.39-13.30)$ & 0.04 \\
\hline Intergenic region & rs4794820 & GG & 238 & $2.24(1.31-3.80)$ & 92 & $5.74(2.54-13.00)$ & 0.05 \\
\hline
\end{tabular}

SNP: single nucleotide polymorphisms. ${ }^{\#}$ : p-values for association of remittent asthma and infection ranged between $0.05 \times 10^{-3}$ and $2.2 \times 10^{-3}$ in subjects with the nonrisk genotype and between $8.0 \times 10^{-4}$ and $1.3 \times 10^{-5}$ in subjects with the risk genotype. The p-values for interaction that were $<0.05$ in this table still reached that significance level when they were obtained by simulations, except for rs9303281 and rs4794820 ( $p=0.06)$. Bold values indicate significance.

between infection and early-onset asthma (or remittent asthma) was further enhanced when children with $17 q 21$ risk variants were exposed to ETS in early life. The present study supports earlier findings showing the importance of early life events in the association between $17 q 21$ variants and asthma [16].

\section{Infections and asthma}

Lower respiratory tract infections may identify children with pre-existing physiological or immunological abnormalities, or may provide a first trigger to start wheezing in infants who are prone to develop asthma. Otherwise, it has been suggested that viral respiratory infections and asthma may be causally

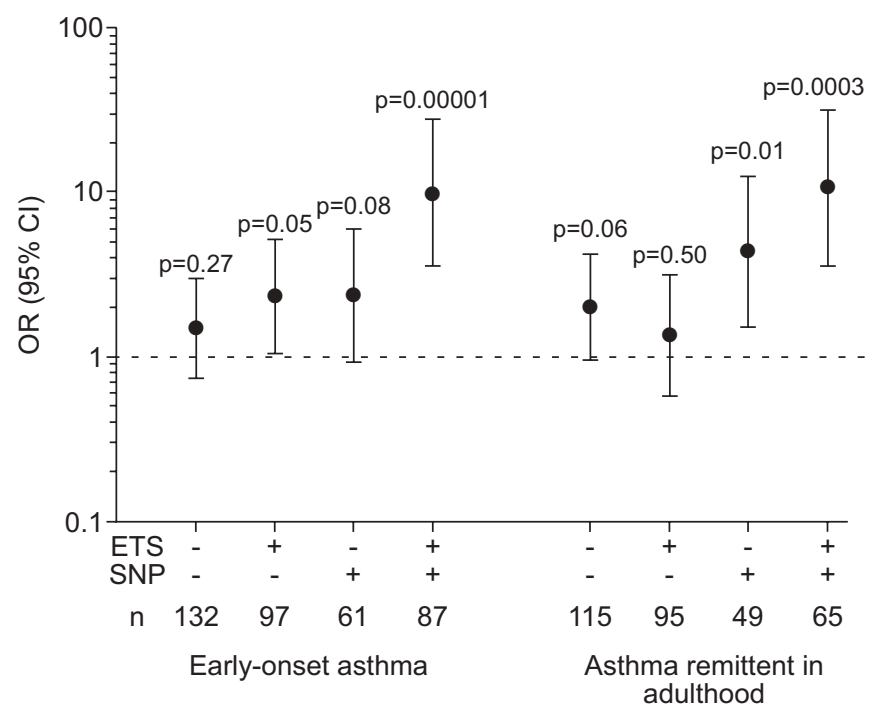

FIGURE 1. Association of asthma (early-onset asthma and asthma remittent in adulthood) and early respiratory infection, according to environmental tobacco smoke (ETS) exposure in early life (yes: +, no: -) and rs8069176 genotype (single nucleotide polymorphism (SNP): +: GG; -: AG+AA). related. There is some evidence of a causal link, including recent findings from an experimental mouse model showing that innate immune activation by viral respiratory infection can lead to the development of chronic inflammatory airway disease $[7,8,22]$. Infants with $17 q 21$ risk variants may respond differently to lung injury caused by respiratory viral infections, which may increase their susceptibility to develop recurrent wheezing or asthma. However, we cannot draw conclusions regarding the causality of association between early respiratory infection and asthma, and if we assume a noncausal association between infection and asthma, an explanation for our findings might be that $17 \mathrm{q} 21$ variants increase the risk to develop asthma by interacting with risk factors underlying early virus-induced wheezing. Gene-gene or gene-environment interaction between 17q21 variants and common risk factors for respiratory infection and asthma (such as innate immune gene variants) could thus influence the risk of asthma.

\section{A large genomic region of interest}

The function of the studied 17q21 genes is largely unknown, especially with respect to asthma. A relationship between ORMDL3, viral infection, and asthma was suggested by HIROTA et al. [14] who found that ORMDL3 expression was strongly induced in an experimental model of viral stimulation. A recent study reported that ORMDL3 facilitated endoplasmic reticulum mediated inflammatory responses [23]. Among the 12 SNPs studied, one belongs to ORMDL3 while the other ones are intergenic (three SNPs) or belong to other genes, IKZF3 (one SNP), involved in the regulation of lymphocyte development, ZPBP2, or zona pellucida-binding protein 2 (one SNP), and GSDML (six SNPs), encoding one of the gasdermin proteins implicated in epithelial barrier function and skin differentiation [24]. These 17q21 SNPs are strongly associated with transcript levels of ORMDL3 [13], and, as found more recently, with transcript levels of GSDML, indicating that both ORMDL3 and GSDML are coregulated by cis-acting genetic variants [25]. Therefore, our epidemiologic 
observations are consistent with biological findings which suggest that genetic variants act over a large genomic region, playing a role in transcriptional activity of at least three genes (ZPBP2, GSDML and ORMDL3) [25].

\section{Lung function and atopy}

Association between 17q21 SNPs and FEV1 was not found in EGEA and other populations, but in these populations lung function was not measured in early childhood $[15,16]$. There is ample evidence that diminished airway size is a risk factor for wheezing during viral infections in early life [4]. It could, therefore, also be speculated that $17 q 21$ variants modify association between a reduced pulmonary function in infancy and early-onset asthma. A reduced maximal flow at functional residual capacity ( $V^{\prime}$ max,FRC) during the first year of life was associated with transient, but not persistent, early wheezing, a phenotype which is strongly related to viral infections, in the Tucson Children's Respiratory Study [26]. However, it has also been shown that diminished values of $V^{\prime}$ max,FRC at 1 month are associated with persistent wheeze at 11 yrs of age in children from the Perth study [27]. EGEA probands were recruited at age $\geqslant 7 \mathrm{yrs}$ and, therefore, our study cannot be directly compared with birth cohort studies such as the Tucson and Perth studies [26-28], in as much as children with asthma at school age were included more frequently in EGEA.

Both atopy and early life respiratory viral infections are independently associated with subsequent asthma, and the combination of atopy and respiratory infections has been associated with a strongly increased risk to develop asthma [29]. Most studies show that 17q21 SNPs are not associated with atopy or total $\mathrm{IgE}$ as such, but possibly with atopic asthma [15-17]. However, because of the strong association between atopy and asthma in EGEA children (almost $90 \%$ of the children with asthma were atopic), we could not perform separate analyses for atopic and nonatopic asthma.

\section{Persistent and remittent asthma in young adulthood}

The longitudinal design of EGEA provides a unique opportunity to study the persistence of childhood asthma into young adulthood. The study did not have sufficient statistical power to perform separate analyses according to the age at onset among subjects with persistent or remittent asthma; however, the majority of children with asthma (62\%) had a first asthma attack at age $\leqslant 4$ yrs. The modifying effect of $17 q 21$ variants on the association between infection and asthma was most pronounced for asthma that remitted in young adulthood, suggesting that the functional role of 17q21 variants may be restricted to early life events, which may be outgrown at a later age.

\section{ETS, early events and epigenetics}

We studied whether ETS exposure in early life further modified associations between respiratory infection and asthma, although this resulted in relatively small subgroups. The additional modifying effect of early life ETS exposure is, however, plausible, since ETS exposure has been shown to influence the child's lung function and immune system. Children exposed to ETS in utero or in early life exhibit small but clear deficits in lung function, and there has been clear evidence of a dose-dependent relationship between the amount smoked by mothers and lung function in children [30].
It has also been shown that exposure to ETS in early life can influence signalling through innate immune receptors, which may be implicated in the increased predisposition to infection in ETS exposed infants [31]. Moreover, in mouse models, cigarette smoke has been shown to affect antiviral pro-inflammatory processes [10]. VERLAAN et al. [25] suggested that environmental triggers and common $17 q 21$ variants may influence epigenetic states by shifting the equilibrium in favour of one of the chromatin conformations resulting in changes in gene expression. The very early window of expression and the interaction with ETS both support the hypothesis of a role of epigenetic changes.

\section{Limitations}

Sub-group analyses led to relatively small numbers of subjects, especially when taking ETS exposure into account. We cannot rule out false negative results due to inadequate power. Although results were not modified by removal of influential subjects from the study sample, interpretation should be cautious and replication is needed to confirm our observations. Another main limitation of our study was that viral respiratory infection was assessed retrospectively by questionnaire. We did not have objective data confirming that the self-reported earlylife respiratory infections were viral, although it is wellestablished that the majority of respiratory illnesses in infancy are caused by viral infections [32]. Parents of children with asthma could have been more likely to recall a respiratory infection episode during the first two years of their child's life than parents of children without asthma. Although a recall bias may have resulted in an overestimation of the association between infection and asthma, it cannot explain the modifying effect of 17q21 variants on this association. We could not assess the role of severity, nor of specific viral infections, such as rhinovirus or RSV bronchiolitis. Recently, outpatient wheezing illness with rhinovirus infection was shown to be a much stronger predictor of subsequent asthma than wheezing with RSV [1]. It would be of interest not only to replicate our findings in a prospective study, but also to explore whether $17 q 21$ variants interact differently with rhinovirus or RSV bronchiolitis. To prevent false-positive results due to potential confounders or data stratification, $\mathrm{p}$-values for tests of interaction of 17q21 SNPs with infection were computed by simulations and led to the same results as those shown here. We did not apply the Bonferroni correction to correct for multiple testing since it would be much too conservative given the high level of LD among the 12 SNPs analysed. Moreover, further haplotype analysis led to the same results as those shown here.

In conclusion, this study shows an important role of $17 \mathrm{q} 21$ variants, early respiratory infection and early exposure to ETS in early-onset asthma. Our longitudinal data also suggest that $17 q 21$ variants modified the association of early respiratory infection and an asthma phenotype that does not persist into adulthood. Therefore, our results add to the evidence that the relevant window of expression for 17q21 variants is early in life.

\section{SUPPORT STATEMENT}

This study was supported by the French Ministry of Higher Education and Research, University Paris Diderot-Paris 7, grants from the French Agency for Environmental and Occupational Health Safety (grant AFSSET-APR-SE-2004), the French National Agency for Research (grants ANR 05-SEST-020-02/05-9-97 and ANR 06-CEBS), Merck 
Sharp \& Dohme (MSD), Hospital programme of clinical research (PHRC)-Paris, and GABRIEL, a multidisciplinary study to identify the genetic and environmental causes of asthma in the European Community (contract $\mathrm{n}^{\circ} 01896$ under the Integrated Programme LSH-2004-1.2.5-1 Post genomic approaches to understand the molecular bias of asthma aiming at a preventive or therapeutic control) L.A.M. Smit is supported by a European Academy of Allergology and Clinical Immunology-Global Allergy and Asthma European Network (EAACI-GA ${ }^{2}$ LEN) exchange fellowship award.

\section{STATEMENT OF INTEREST}

A statement of interest for this study can be found at www.erj. ersjournals.com $/ \mathrm{misc} /$ statements.dtl

\section{ACKNOWLEDGEMENTS}

The authors would like to thank the EGEA Cooperative Group: Coordination: F Kauffmann; F Demenais (genetics); I Pin (clinical aspects). Respiratory epidemiology: M Korobaeff (Egea1), F Neukirch (Egea1) (both Inserm U 700, Paris, France); I Annesi-Maesano (Inserm U 707, Paris, France); F Kauffmann, N Le Moual, R Nadif, MP Oryszczyn (Inserm U 780, Villejuif, France); V Siroux (Inserm U 823, Grenoble, France). Genetics: J Feingold (Inserm U 393, Paris, France); E Bouzigon, F Demenais, MH Dizier (Inserm U 946, Paris, France); I Gut, M Lathrop (CNG, Evry, France). Clinical centres: I Pin, C Pison (Grenoble, France); D Ecochard (Egea1), F Gormand, Y Pacheco (Lyon, France); D Charpin (Egea1), D Vervloet (Marseille, France); J Bousquet (Montpellier, France); A Lockhart (Egea1)(Cochin, Paris, France), R Matran (Marseille, France); E Paty, P Scheinmann (Necker, Paris, France); A Grimfeld, J Just (Trousseau, Paris). Data and quality management: J Hochez (Egea1) (Inserm ex-U155, Paris); N Le Moual, C Ravault (Inserm U 780, Villejuif); N Chateigner (Inserm U 794, Evry); J Ferran (Grenoble, France).

The authors thank all those who participated to the setting of the study and on the various aspects of the examinations involved. The authors are grateful to the three CIC-Inserm of Necker, Grenoble and Marseille who supported the study and in which subjects were examined at the second survey. They are indebted to all the individuals who participated, and without whom the study would not have been possible.

\section{REFERENCES}

1 Jackson DJ, Gangnon RE, Evans MD, et al. Wheezing rhinovirus illnesses in early life predict asthma development in high-risk children. Am J Respir Crit Care Med 2008; 178: 667-672.

2 Sigurs N, Bjarnason R, Sigurbergsson F, et al. Respiratory syncytial virus bronchiolitis in infancy is an important risk factor for asthma and allergy at age 7. Am J Respir Crit Care Med 2000; 161: 15011507.

3 Stein RT, Sherrill D, Morgan WJ, et al. Respiratory syncytial virus in early life and risk of wheeze and allergy by age 13 years. Lancet 1999; 354: 541-545.

4 Martinez FD. Heterogeneity of the association between lower respiratory illness in infancy and subsequent asthma. Proc Am Thorac Soc 2005; 2: 157-161.

5 Bartlett NW, McLean GR, Chang YS, et al. Genetics and epidemiology: asthma and infection. Curr Opin Allergy Clin Immunol 2009; 9: 395-400.

6 Thomsen SF, van der Sluis S, Stensballe LG, et al. Exploring the association between severe respiratory syncytial virus infection and asthma: a registry-based twin study. Am J Respir Crit Care Med 2009; 179: 1091-1097.

$7 \mathrm{Wu}$ P, Dupont WD, Griffin MR, et al. Evidence of a causal role of winter virus infection during infancy in early childhood asthma. Am J Respir Crit Care Med 2008; 178: 1123-1129.
8 Kusel MM, de Klerk NH, Kebadze T, et al. Early-life respiratory viral infections, atopic sensitization, and risk of subsequent development of persistent asthma. J Allergy Clin Immunol 2007; 119: $1105-1110$.

9 Singh AM, Moore PE, Gern JE, et al. Bronchiolitis to asthma: a review and call for studies of gene-virus interactions in asthma causation. Am J Respir Crit Care Med 2007; 175: 108-119.

10 Stampfli MR, Anderson GP. How cigarette smoke skews immune responses to promote infection, lung disease and cancer. Nat Rev Immunol 2009; 9: 377-384.

11 Janssen R, Bont L, Siezen CL, et al. Genetic susceptibility to respiratory syncytial virus bronchiolitis is predominantly associated with innate immune genes. J Infect Dis 2007; 196: 826-834.

12 Le Souef PN. Gene-environmental interaction in the development of atopic asthma: new developments. Curr Opin Allergy Clin Immunol 2009; 9: 123-127.

13 Moffatt MF, Kabesch M, Liang L, et al. Genetic variants regulating ORMDL3 expression contribute to the risk of childhood asthma. Nature 2007; 448: 470-473.

14 Hirota T, Harada M, Sakashita M, et al. Genetic polymorphism regulating ORM1-like 3 (Saccharomyces cerevisiae) expression is associated with childhood atopic asthma in a Japanese population. J Allergy Clin Immunol 2008; 121: 769-770.

15 Galanter J, Choudhry S, Eng C, et al. ORMDL3 gene is associated with asthma in three ethnically diverse populations. Am J Respir Crit Care Med 2008; 177: 1194-1200.

16 Bouzigon E, Corda E, Aschard H, et al. Effect of 17q21 variants and smoking exposure in early-onset asthma. N Engl J Med 2008; 359: 1985-1994.

17 Bisgaard H, Bonnelykke K, Sleiman PM, et al. Chromosome 17q21 gene variants are associated with asthma and exacerbations but not atopy in early childhood. Am J Respir Crit Care Med 2009; 179: 179-185.

18 Flory JH, Sleiman PM, Christie JD, et al. 17q12-21 variants interact with smoke exposure as a risk factor for pediatric asthma but are equally associated with early-onset versus late-onset asthma in North Americans of European ancestry. J Allergy Clin Immunol 2009; 124: 605-607.

19 Kauffmann F, Dizier MH, Pin I, et al. Epidemiological study of the genetics and environment of asthma, bronchial hyperresponsiveness, and atopy: phenotype issues. Am J Respir Crit Care Med 1997; 156: S123-S129.

20 Siroux V, Boudier A, Bousquet J, et al. Phenotypic determinants of uncontrolled asthma. J Allergy Clin Immunol 2009; 124: 681-687.

21 Smit LA, Siroux V, Bouzigon E, et al. CD14 and toll-like receptor gene polymorphisms, country living, and asthma in adults. Am J Respir Crit Care Med 2009; 179: 363-368.

22 Kim EY, Battaile JT, Patel AC, et al. Persistent activation of an innate immune response translates respiratory viral infection into chronic lung disease. Nat Med 2008; 14: 633-640.

23 Cantero-Recasens G, Fandos C, Rubio-Moscardo F, et al. The asthma-associated ORMDL3 gene product regulates endoplasmic reticulum-mediated calcium signaling and cellular stress. Hum Mol Genet. 2010; 19: 111-121.

24 Tamura M, Tanaka S, Fujii T, et al. Members of a novel gene family, Gsdm, are expressed exclusively in the epithelium of the skin and gastrointestinal tract in a highly tissue-specific manner. Genomics 2007; 89: 618-629.

25 Verlaan DJ, Berlivet S, Hunninghake GM, et al. Allele-specific chromatin remodeling in the ZPBP2/GSDMB/ORMDL3 locus associated with the risk of asthma and autoimmune disease. Am J Hum Genet 2009; 85: 377-393.

26 Martinez FD, Wright AL, Taussig LM, et al. Asthma and wheezing in the first six years of life. The Group Health Medical Associates. N Engl J Med 1995; 332: 133-138. 
27 Turner SW, Palmer LJ, Rye PJ, et al. The relationship between infant airway function, childhood airway responsiveness, and asthma. Am J Respir Crit Care Med 2004; 169: 921-927.

28 Delacourt C, Benoist MR, Le Bourgeois M, et al. Relationship between bronchial hyperresponsiveness and impaired lung function after infantile asthma. PLoS One 2007; 2: e1180.

29 Sly PD, Boner AL, Bjorksten B, et al. Early identification of atopy in the prediction of persistent asthma in children. Lancet 2008; 372: 1100-1106.
30 Cook DG, Strachan DP, Carey IM. Health effects of passive smoking. 9. Parental smoking and spirometric indices in children. Thorax 1998; 53: 884-893.

31 Prescott SL. Effects of early cigarette smoke exposure on early immune development and respiratory disease. Paediatr Respir Rev 2008; 9: 3-10.

32 Gern JE, Rosenthal LA, Sorkness RL, et al. Effects of viral respiratory infections on lung development and childhood asthma. J Allergy Clin Immunol 2005; 115: 668-675. 